\title{
Characteristic findings of alstrom syndrome with a case report
}

\author{
Fatma Silan $^{1 *}$, Savas Gur ${ }^{2}$, Laliz Esin Kadioglu ${ }^{3}$, Sinem Atik Yalcintepe ${ }^{1}$, Kubilay Ukinc ${ }^{4}$, \\ Ahmet Uludag ${ }^{1}$, Ozturk Ozdemir ${ }^{1}$ \\ ${ }^{1}$ Medical Genetics Department, School of Medicine, Canakkale on Sekiz Mart University, Canakkale, Turkey \\ ${ }^{2}$ Internal Medicine Department, School of Medicine, Canakkale on Sekiz Mart University, Canakkale, Turkey \\ ${ }^{3}$ Children's Health and Diseases Department, School of Medicine, Canakkale on Sekiz Mart University, Canakkale, Turkey \\ ${ }^{4}$ Endocrinology Department, School of Medicine, Canakkale on Sekiz Mart University, Canakkale, Turkey \\ Email: fsilan@yahoo.com
}

Received 7 May 2012; revised 7 June 2012; accepted 15 June 2012

Copyright (C) 2013 Fatma Silan et al. This is an open access article distributed under the Creative Commons Attribution License, which permits unrestricted use, distribution, and reproduction in any medium, provided the original work is properly cited.

\begin{abstract}
Alstrom Syndrome is an autosomal recessive genetic disorder affecting multiple systems. The characteristic features of this syndrome are obesity, type 2 diabetes mellitus, rod-cone dystrophy, hearing loss. Developmental delay, nistagmus, dilated cardiomyopathy, hypertension, recurrent pulmonary infections, short stature, hepatic and renal failure endocrine abnormalities are other clinical features of this syndrome. Here we report on a case with Alström Syndrome at the age of thirteen. He was referred to medical genetics clinic from endocrinology where he has been watched because of obesity, type 2 diaibetes mellitus and hypogonadism. His parents were first degree relatives. He was also $95 \%$ blind and had hearing loss. When we looked up these findings with a clinical diagnosis we thought about Alström Syndrome. It is a rare disease and difficult to make differential diagnosis with other similar syndromes, therefore this case will be a good example of Alstrom Syndrome for the literature.
\end{abstract}

Keywords: Alstrom Syndrome; Obesity; Hearing Loss

\section{INTRODUCTION}

Alstrom Syndrome (OMIM 203800) is a rare progressive autosomal recessive genetic disorder affecting multiple systems with rod-cone dystrophy, hearing loss, obesity, type 2 diabetes mellitus and mostly caused by mutations in ALMS1 (2p13) [1]. Approximately 700 cases have been known with this syndrome [3], the prevalence is less than 1:100,000 [2]. Rod-cone dystrophy incidence is $100 \%$ at this syndrome and it occurs in infancy [3]. Other

\footnotetext{
"Corresponding author.
}

features respectively to incidence are obesity (birth-age 5), short stature (puberty-adult), insulin resistance/type 2 diabetes mellitus (4 - 30 years), hypogonadotropic hypogonadism (1 - 3 years), urologic disease (adolescenceadult), progressive sensorineural hearing loss (2 - 25 years), hepatic and renal failure (adolescence-adult), dilated cardiomyopathy (2 weeks - 4 months), developmental delay (birth-adolescence) [3,4]. Other variable supportive findings are recurrent pulmonary infections, normal digits, hyperlipidemia, scoliosis, flat wide feet, hypothyroidism, hypertension, urinary dysfunction, growth hormone deficiency and alopecia [1].

In differential diagnosis there are similar diseases like Bardet-Biedl Syndrome which is sharing some same features with Alstrom syndrome, Achromatopsia that affects retina, Leber congenital amaurosis which affects retina again and early-onset dilated cardiomyopathy which can be inherited autosomal dominant or autosomal recessive [3].

Diagnostic criteria change in different ages [1]. It can be examined in three groups as birth-2 years, 3 - 14 years, 15 year-adulthood. Our case was 13 years old and we diagnosed him with the criteria of second group (3 - 14 years) and reported in this paper for especially considering this syndrome if there is a patient with obesity, insulin resistance, vision and hearing problems.

ALMS1 gene (MIM 606844) has 23 exons and 12,871 base pairs encoding a protein contains 4169 amino acids [1,5]. The ALMS1 protein plays an important role in cilia function and intraflagellar transport. Marshall et al. (2007) reported mutations in exons 16, 10, 8, 12 and 18 in 79 patients [1]. Collin et al. (2002) has studied this gene with Real Time PCR and sequencing to explain different clinical findings and phenotypes of the patients [6]. Hearn et al. detected six different mutations in seven families to 
confirm that ALMS1 gene mutations are the reasons of Alstrom Syndrome [7].

\section{CASE}

Our case was a 13-year-old male followed up at endocrinology clinic because of obesity, type 2 diabetes mellitus, hypogonadism and hyperlipidemia. He was going on also ophthalmology clinic for rod-cone dystrophy and photophobia. He was referred to our clinic with the preliminary diagnosis of Bardet-Biedl Syndrome or Alstrom Syndrome.

His parents were first degree relatives, mother was 43 years old and father was 49 years old. He was born a full-term normal delivery with a birth weight of $2500 \mathrm{~g}$. The present weight, height and BMI were $78 \mathrm{~kg}, 160 \mathrm{~cm}$ and 30.4 respectively. He was the third child, before his pregnancy her mother got two spontan abortuses and she had preeclampsia during her pregnancy. His parents, sister, brother and other family members in the pedigree had no history like our patient.

There had been a history of hypertension after birth as sistolic blood pressure was $200 \mathrm{mmHg}$. He has had hearing loss and visual impairment since birth. His physical examination revealed truncal obesity, visual loss, hearing loss, acanthosis nigricans in the cervical area and gynecomastia. He had adenoidectomy operation when he was 10 years old. Also we learned that he had recurrent otitis media and glue ear. He also had recurrent pulmonary infections and chronic bronchitis.

Laboratory tests revealed fasting glucose: $104.3 \mathrm{mg} / \mathrm{dl}$, hyperinsulinism (271 uIU/ml) and OGTT 75 gr 120': 278.5 (Type 2 Diabetes Mellitus), HbA1c: 7\%, C-peptide: $10.9 \mathrm{ng} / \mathrm{ml}$, Total testosteron: $1.07 \mathrm{ng} / \mathrm{ml}$, Triglyceride: $566.4 \mathrm{mg} / \mathrm{dL}$, LDL Cholesterol: $112.3 \mathrm{mg} / \mathrm{dL}$, HDL Cholesterol: $26 \mathrm{mg} / \mathrm{dL}$, Total Cholesterol: $219 \mathrm{mg} / \mathrm{dL}$ GH: $<0.05 \mathrm{ng} / \mathrm{ml}(\mathrm{N})$, FSH: $8.95 \mathrm{mIU} / \mathrm{ml}(\mathrm{N}), \mathrm{LH}: 6.79$ $\mathrm{mIU} / \mathrm{ml}$ (N), TSH: $1.68 \mathrm{uIU} / \mathrm{mL}$, fT3: $2.87 \mathrm{pg} / \mathrm{mL}$, fT4: 0.833 ng/dL, ACTH: 25.5 pg/ml, Cortisol: 5.84 .

His audiometric evaluation revealed a mild degree of sensorineural hearing loss and in visual examination there was a difficulty with the patient because of mild mental retardation. There has been bilateral back subcapsular cataract, normal cornea and normal fundus and he has refractive errors and using glasses for it.

Abdomen USG was normal expect liver size was enlarged and paranchim seemed grade 2 hepatosteatosis. Chest X-ray, bone mineral densitometry, echocardiography were normal. He was not cooperative with respiratory function test but the result seems like normal.

ALMS1 mutation analysis has been studied, it was reported that there was no mutation in ALMS1 gene.

When we looked up the components of Alstrom Syndrome, these were well-matched with our patient: Consanguineous marriage of parents, developmental delay, obesity, nystagmus, visual impairment, hearing loss, chronic otitis media, hypertension, hyperinsulinemia, type 2 diabetes mellitus, enlarged liver, elevated levels of cholesterol and triglyceride, euthyroid patient syndrome and male hypogonadism. It is known as a rare syndrome and should be thought of differential diagnosis with obesity, endocrine abnormalities, visual and hearing problems, so we reported this case to be useful for other patients.

\section{DISCUSSION}

Alstrom Syndrome is an autosomal recessive, single gene disorder (ALMS1-2p13) characterized by childhood obesity associated with hyperinsulinemia, and type 2 diabetes mellitus, progressive cone-rod dystrophy leading to blindness, sensorineural hearing loss and function loss of multiple organs [1,5]. In our case initial manifestations were visual problems, photophobia, obesity and hearing impairment. These had presented during the first year of life.

As Marshall et al. (2007) categorized the features of Alstrom syndrome our patient had similar findings like sensory loss, endocrinological disturbances, developmental delay, hypertension [1].

Alstrom Syndrome generally seems like Bardet-Biedl Syndrome. Bardet-Biedl Syndrome has some differancies like polydactyly, brachidactyly, syndactyly, hypodontia, $50 \%$ mental retardation and mutations of BBS gene [8]. It is very important while making diagnosis similar syndromes should be considered. Mendioroz et al. noticed that in their paper [9] and we also thought before our patient's diagnosis. In an evalution of 182 cases by Marshall et al. one patient had polydactyly with ALMS1 gene mutation [4]. Then we shouldn't think polydactyly never seems with Alstrom Syndrome.

Our patient had chronic bronchitis, we learned that he had pulmonary infections more than twice every year. As Marshall et al. described 53\% of 182 cases had chronic bronchitis [4].

It was reported in an investigation paper with 182 cases of Alstrom Syndrome 38\% of patients had no cardiac failure (age range, 2 - 33 years), although there is a risk for developing dilated cardiomyopathy (DCM) in the future. Dilated cardiomyopathy occurred in $62 \%$ of patients. They notified that patients could be divided into two groups: infant and adult onset. Infant onset patients were $43 \%$ of patients, most of them survived and cardiac functions were without problem for three years. But between ages 5 and 36 years 24 of these patients had DCM recurrence and 10 had died. Second group was $18 \%$ of patients had no cardiac failure in infancy but developed DCM as adolescents or adults (age range, 7 - 32 years). These patients' diagnosis was not good, 11 of 33 patients died [4]. According to our patient's echocardiography, there weren't any congenital or other cardiac problems. 
But with this information we took him to cardiac controls with a period of six months. We know that DCM can develop in any time at the rest of his life.

Our patient mentioned regurgitation after meals and described gastroeosophageal reflux. Marshall et al. reported 35 patients of 182 had gastroeosophageal reflux. They also reported $92 \%$ of patients had elevation in liver transaminase levels [4]. But our patient had normal rate of liver transaminase levels.

Urologic problems and abnormal voiding patterns were reported in $48 \%$ of patients in Marshall et al.'s investigation. Urinary tract infections were common at the age range of 2 - 40 years [4]. Our case also had recurrent urinary tract infections.

Hypertension prevelance in Alstrom Syndrome is 30\% [4], our patient was hypertensive, but kidney function tests were normal. We planned controls of these tests because of renal failure risk in the future.

Marshall et al. reported hypergonadotropic and hypogonadotropic hypogonadism were common in males (77\%) [4]. Our patient had normogonadotropic hypogonadism, this would be a new information for other patients and for the literature.

There are a few cases with Alstrom Syndrome reported from Turkey [10-12]. This syndrome is really rare or it is not known clearly so it many cases maybe can not be diagnosed. Satman et al. reported three sisters with this syndrome [10] and this shows that we usually see autosomal recessive manner in Alstrom Syndrome. In Turkey consanguineous marriage prevalance is $25 \%$ and with this condition autosomal recessive diseases are frequent in our country. But if Alstrom Syndrome is reported with only a few cases we suspect are there many patients with this syndrome without true diagnosis?

ALMS1 is a big gene has $12.6 \mathrm{~kb}$ open reading frame which encodes 4169 amino acids so new mutations are expected, but each mutation can not be with the typical phenotype, then diagnosis will be very difficult. Genotype-phenotype correlations showed especially the mutations on 16. Exon one of 23 exons in ALMS1 geneended with typical phenotype, in a big per cent of patients mutations determined on exons $7,10,16$. Mutations on other exons may show mild phenotypes [5]. Our patient has well-matched clinical findings with Alstrom Syndrome, but there is no ALMS1 mutation. Could there be a new mutation with this syndrome different from ALMS1?

\section{CONCLUSION}

The gene is big and mutation analysis is very difficult and expensive so all patients with diabetes mellitus or obesity can not be a candidate for mutation analysis. Actually cases with early onset obesity (6 months) and diabetes mellitus, short stature, hypogonadism, gastroeoso- phageal reflux, recurrent otitis media, photophobia, gingivitis, light yellow-brown discolored enamel bands on teeth should be considered for ALMS1 gene mutation analysis and a lot of patients could be diagnosed with this analysis.

A well known clinical spectrum will increase possibility of making diagnosis, multidisciplinary management of patients will decrease morbidity and mortality with Alstrom Syndrome.

\section{REFERENCES}

[1] Marshall, J., Beck, S., Maffei, P., et al. (2007) Alstrom syndrome. European Journal of Human Genetics, 15, 11931202.

[2] Minton, J.A., Owen, K.R., Ricketts, C.J., et al. (2006) Syndromic obesity and diabetes: Changes in body composition with age and mutation analysis of ALMS1 in 12 United Kingdom kindreds with Alstrom syndrome. The Journal of Clinical Endocrinology \& Metabolism, 91, 31103116. doi:10.1210/jc.2005-2633

[3] NCBI (2012) “Bookshelf” gene reviews: Alström syndrome.

http://www.ncbi.nlm.nih.gov/bookshelf/br.fcgi?book=gen e\&part=alstrom

[4] Marshall, J.D., Bronson, R.T., Collin, G.B., et al. (2005) New Alström syndrome phenotypes based on the evaluation of 182 cases. Archives of Internal Medicine, 165, 675-683. doi:10.1001/archinte.165.6.675

[5] OMIM 606844.

[6] Collin, G.B., Marshall, J.D., Ikeda, A., et al. (2002) Mutations in ALMS1 cause obesity, type 2 diabetes and neurosensory degeneration in Alström syndrome. Nature Genetics, 31, 74-78.

[7] Hearn, T., Renforth, G.L., Spalluto, C., et al. (2002) Mutation of ALMS1, a large gene with a tandem repeat encoding 47 amino acids, causes Alström syndrome. Nature Genetics, 31, 79-83.

[8] OMIM 209900.

[9] Mendioroz, J., Bermejo, E., Marshall, J.D., et al. (2008) Alström syndrome: Clinical and genetic features, and a diagnostic guide to foresee complications. Medicina Clínica, 131, 741-746. doi:10.1016/S0025-7753(08)75490-3

[10] Satman, I., Yilmaz, M.T., Gürsoy, N., et al. (2002) Evaluation of insulin resistant diabetes mellitus in Alström syndrome: A long-term prospective follow-up of three siblings. Diabetes Research and Clinical Practice, 56, 189-196. doi:10.1016/S0168-8227(02)00004-9

[11] Koray, F., Dorter, C., Benderli, Y., et al. (2001) Alstrom syndrome: A case report. Journal of Oral Science, 43, 221-224. doi:10.2334/josnusd.43.221

[12] Ucar, T., Berberoglu, M., Ocal, G., et al. (2003) Metabolic, endocrine and clinical findings in a case with alstrom syndrome. Journal of Ankara Medical School, 25, 143148. 